\title{
Reframe the health debate, minister urges
}

$\mathrm{H}$ ealth care providers, policymakers and patients need to change the discussion surrounding the health care system to focus more on remodelling preventive and primary care, and addressing the social determinants of health, as opposed to worrying about monumental costs, says Alberta's Health Minister Fred Horne.

"The real question isn't the total cost of public health care. But the real question is the value derived from that," Horne said in the keynote closing address to the first Summit on Sustainable Health and Health Care on Oct. 31 in Toronto, Ontario. "We've had a system focused traditionally on money ... My province is committed to a completely new type of system focused on the needs of individuals, families and communities."

Sustainability of the health care system can be achieved through refocusing the system on preventive and primary care, instead of acute care, to ensure that the aging population isn't putting further strain on the system, Horne said. "We need to focus increasingly on the health status of our citizens."

Roughly $10 \%$ of Alberta's population received a magnetic resonance imaging scan in 2007 but that didn't reduce the number of people waiting for treatment in acute care centres, which begs the question of the appropriate use of these technologies, Horne said. "A province that has the privilege of building more hospitals sees a very high rate of the utilization of acute care. This is increasingly an issue when it comes to chronic disease management."

"We are experiencing an increased prevalence of diabetes and hypertension. We're seeing, much to our dismay, an increased number of patients in hospitals and complications about those diseases."

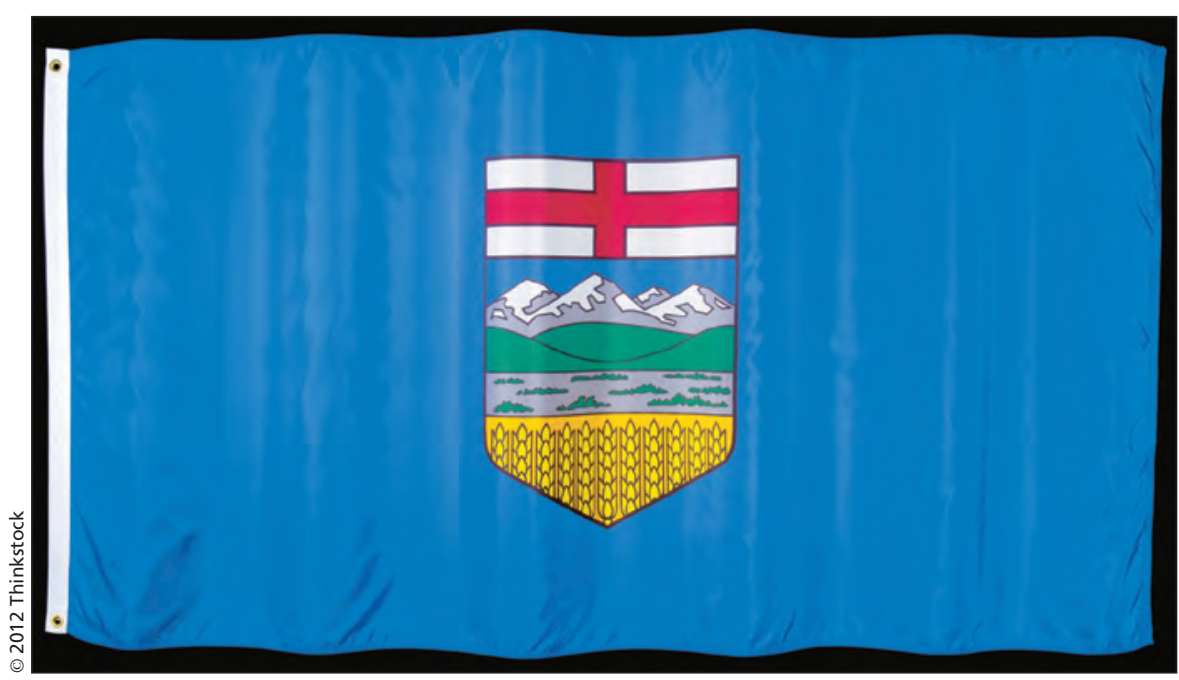

The province of Alberta asserts that it is overhauling its health services to focus more attention on preventive care and the underlying determinants of health.

Alberta's approach will be to provide every citizen an opportunity to interact with a primary health care team, Horne said. "We've introduced team-based care, piloted different versions of it. Yet, to engage populations in the transformation of the health care system, we need to focus on the relationship between providers and patients."

"We're going further and we're thinking about, in a very concrete way, the social determinants of health using this platform of community-based care that will survive the budget cycle," he added.

Treatment for addictions, mental health services, child care, affordable housing and income support services will be linked to the provision of primary care, Horne said. "We asked questions like: What are things being done in the hospital now that can be done in communities?"

"We're starting a movement at the most fundamental level of society the level of community. We will actually be giving the communities the opportunity to develop and present proposals to meet our basic eligibility. ... We're sharing community health needs assessment data with people in the community to look at it and discuss it and to tell us what they think, in terms of the design, would best meet their needs."

The health care system can be made more efficient, and therefore, more sustainable through such an integrated approach, Horne told the roughly 300 health experts at the summit.

Alberta wants to offer its residents a "home within the health care system," he added. "We made a decision in the government to focus on the 'front door' of the health system, which we believe to be primary health care - a community driven model - and other changes can be achieved in our system as a result of our approach. ... Changes are going to drive greater efficiencies in our hospitals and all care at a tertiary level." - Adam Miller, CMAJ

CMAJ 2012. DOI:10.1503/cmaj.109-4336 